\title{
Status of beedi rollers in urban slum area of Dharwad city, India
}

\author{
Lata Radhakrishna Kollur ${ }^{1 *}$, Akshath Kumar Shetty ${ }^{1}$, Drakshayani Pandurang Kongwad, \\ Jayprakash Chowti ${ }^{2}$
}

\footnotetext{
${ }^{1}$ Department of Community Medicine, SDMCMS\&H, Manjushree Nagar, Sattur, Dharwad, Karnataka, India

${ }^{2}$ Principal, SDMCMS\&H, Manjushree Nagar, Sattur, Dharwad, Karnataka, India
}

Received: 12 September 2015

Revised: 26 September 2015

Accepted: 09 October 2015

\section{*Correspondence: \\ Dr. Lata Radhakrishna Kollur, \\ E-mail:kollurl@yahoo.com}

Copyright: () the author(s), publisher and licensee Medip Academy. This is an open-access article distributed under the terms of the Creative Commons Attribution Non-Commercial License, which permits unrestricted non-commercial use, distribution, and reproduction in any medium, provided the original work is properly cited.

\begin{abstract}
Background: Beedi is also called as poor man's cigarette. Government estimates total number of beedi workers at about 4.5 million. Women involvement in beedi rolling has been linked to the ease of learning skill, its manual operations, the fact that work can be carried out at home. Beedi rollers are exposed to unburnt tobacco dust through cutaneous and pharyngeal route.

Methods: Community adopted under UHTC, Dept. of Community medicine, SDMCMS\&H, Dharwad, Karnataka. All beedi rollers residing in the Community adopted under UHTC who were involved in beedi rolling since at least last 6 months and willing to participate in the study. Study duration was 2 months (April to June 2014). Preformed pretested questionnaire was used to collect data regarding sociodemographic profile, health problems and knowledge, attitude and practices towards handling of tobacco, urine cotinine test strips. Ethical clearance was obtained from Institutional ethical committee of SDMCMS\&H, Dharwad. Descriptive statistics like percentages and proportions were calculated.

Results: All participants in our study were females and mean age at starting beedi rolling was 15 years. Commonest reason for starting beedi rolling was to support family income. Regarding harmful effects of handling tobacco dust for rolling beedi, 5 (17\%) participants replied positively, whereas remaining $24(82.7 \%)$ participants considered it to be harmless. Washing hands after handling tobacco dust was a common practice of 19 (65.5\%) participants.

Conclusions: Handling tobacco dust is considered harmless by beedi rollers mainly because of ignorance which arises due to illiteracy and becomes their need to support family economically.
\end{abstract}

Keywords: Tobacco, Beedi, Cigarette

\section{INTRODUCTION}

Beedi is also called as poor man's cigarette. Beedi manufacturing on commercial basis is about a century old, although beedi making for own consumption must have been even earlier. ${ }^{1}$ Beedi making is traditional agroforest based industry spread over almost all major states of India. Government estimates total number of beedi workers at about 4.5 million. ${ }^{2}$ Literature points out three systems under which production of beedis is organizedfactory, outwork, contractual system. Of these, most common is contractual system - in this middlemen/contractor supplies raw material to the workers who roll beedis in their respective homes and return rolled beedis to the contractor. Women involvement in beedi rolling has been linked to the ease of learning skill, its manual operations, the fact that work can be carried out at home. ${ }^{1}$ A rising concern is also the involvement of children, particularly girls, in the process of beedi rolling. It appears that the home based nature of work and piece rate system of payment creates conditions for the involvement of family labour, including that of 
children. The poverty, indebtedness, landlessness, the lack of alternative skills, little or no access to credit and other means of livelihood force many women to persist in this occupation. ${ }^{2}$

So the number involved may be more than what we identify.

In Karnataka beedi tobacco accounts for 65 percent of total tobacco area.

In Karnataka, $25 \%$ of the total tobacco production is towards beedi production. Of the four million workers nationally, Karnataka accounts for $12 \% .^{3}$

Beedi rollers are exposed to unburnt tobacco dust through cutaneous and pharyngeal route. ${ }^{4}$

Hence the current study was undertaken with following objectives:

1. To study sociodemographic profile and health problems of female beedi workers.

2. To study their knowledge, attitude and practices regarding hazards of handling tobacco.

\section{METHODS}

A community based cross sectional study was carried out in urban slum area adopted under UHTC .Snow balling sampling technique was used to identify beedi roller. After interviewing and collecting information as per the questionnaire from the initial study participant, the study participant was asked to refer to other possible respondent currently involved in beedi rolling. Study participants were selected till entire population was covered. Those beedi rollers who had left this work were not included in the study.

We could contact 29 beedi workers. Study participants were interviewed using the questionnaire, regarding their socio-economic status, working conditions and health problems. Their knowledge, attitude and practices regarding handling of tobacco, its hazards and opinion regarding involvement of children, pregnant females and lactating mothers was assessed. Observations were made regarding proper lighting, ventilation and overcrowding during the interview. Urine cotinine test was performed on $10 \%$ of the sample i.e. on 6 study participants after obtaining informed consent to study the cutaneous absorption of nicotine. All 6 participants who were selected for the cotinine test were asked about history of consumption/ habit of use of tobacco in any form. Those who said no, were selected for urine cotinine test to know cutaneous absorption of tobacco. Ethical clearance was obtained from institutional ethical committee. Informed consent was obtained from the participant. In case of children consent of parent or guardian was taken.

\section{RESULTS}

In population covered by Urban Health Training Center, most of the house were ill ventilated, lighting was inadequate and overcrowding was present.

There were contractors of two beedi companies functioning in the community. They were providing raw materials needed to prepare beedi and collect them once they were ready.

All participants in our study were females. None of the males were involved in beedi rolling.

Table 1: Distribution of study participants according to age and years spent in beedi making.

Distribution of study participants according to age and years spent in beedi making

\begin{tabular}{|llll|}
\hline $\begin{array}{l}\text { Age in years } \\
\text { at starting } \\
\text { (minimum) }\end{array}$ & $\begin{array}{l}\text { Age in years } \\
\text { at starting } \\
\text { (maximum) }\end{array}$ & $\begin{array}{l}\text { Age in years at } \\
\text { starting (mean) }\end{array}$ & SD \\
\hline 10 & 32 & 15 & 7.20 \\
\hline $\begin{array}{l}\text { Years spent in } \\
\text { beedi making } \\
\text { (minimum) }\end{array}$ & $\begin{array}{l}\text { Years spent in } \\
\text { beedi making } \\
\text { (maximum) }\end{array}$ & $\begin{array}{l}\text { Years spent in } \\
\text { beedi making } \\
\text { (mean) }\end{array}$ & SD \\
\hline 2 & 55 & 27.5 & 13.9 \\
\hline
\end{tabular}

Table 2: Sociodemographic profile of beedi workers.

\begin{tabular}{|ll|}
\hline Sociodemographic profile of beedi workers \\
\hline Marital status \\
\hline Married & 17 \\
\hline Unmarried & 8 \\
\hline Divorced & 1 \\
\hline Widow & 3 \\
\hline Education & \\
\hline Illiterate & 20 \\
\hline Students & 7 \\
\hline Primary school & 1 \\
\hline Secondary school & 1 \\
\hline Religion & \\
\hline Hindu & 4 \\
\hline Muslim & 25 \\
\hline Occupation & 20 \\
\hline Housewife & 7 \\
\hline Student & 2 \\
\hline Maid servant & \\
\hline
\end{tabular}

When asked regarding duration since when they are involved in beedi rolling- minimum duration was 2 years. To maximum of 55 years which gives us idea regarding the approximate minimum age at starting of beedi rolling as 10 years (As aged women were not able to recall exact age). 
When asked regarding source of information, most common was family members and that too, most commonly from mother.

Commonest reason for starting beedi rolling was to support family income. Most of them belonged to class $\mathrm{V}$ of modified B. G. Prasad classification.

The sociodemographic profile of the study participants was as shown below in Table 2 .

They prepare beedies with minimum of 60 beedies/day to maximum of 1600 beedies/day and spend on an average 6.2 hours/day in beedi rolling.

They get Rs. 100/- for rolling 1000 beedies.

When asked,whether they are aware of harmful effects of handling tobacco dust for rolling beedi 5 (17\%) participants replied positively, whereas remaining 24 $(82.7 \%)$ participants considered it to be harmless.

When questioned regarding protective measures majority i.e. $19(65.5 \%)$ said that they wash hands after handling tobacco dust. But they were not practicing any other protective measures to prevent inhalation tobacco dust and cutaneous absorption of nicotine.

Most of them were used to roll beedies inside the house with an exception of 1 participant who used to do it either inside or outside.

Study participants who were not willing to involve children in beedi rolling were $24(82.7 \%)$, whereas 3 $(10.3 \%)$ said they can be utilized in order to finish it faster, answer of remaining $2(6.8 \%)$ participants was do not know.

Table 3: Distribution of participants according to medical condition.

\begin{tabular}{|l|l|}
\hline Medical condition & Number* \\
\hline Hypertension & 6 \\
\hline Diabetes mellitus & 1 \\
\hline Osteoarthritis & 3 \\
\hline Cardiovascular disease & 1 \\
\hline Stroke & 1 \\
\hline Surgery & 2 \\
\hline Hypotension & 1 \\
\hline
\end{tabular}

*One participant may be suffering from $>1$ conditions

2 study participants had congenital defects. Out of 29 study participants, 16 reported no major medical condition.

When asked about inclusion of pregnant and lactating mothers in beedi rolling $27(93.1 \%)$ said can not be involved as they felt that it can be harmful, whereas only $2(6.8 \%)$ said can be involved if need arises.
Health problems like joint pains, backache were commonly reported. Some complained of giddiness, dryness of throat on exposure to tobacco dust.

Medical conditions in study participants were as given in Table 3.

Urine cotinine test was performed in 6 participants who were selected randomly. Out of 6 participants it showed positive result in 2 participants.

\section{DISCUSSION}

Beedi rolling is carried out at household level. Two important raw materials required for beedi making include tendu leaves and unburnt tobacco dust, which are supplied by the contractor. A female beedi roller prepares 50 to 1000 beedies/day. For 1000 beedies prepared by her she gets Rs. 100. If there happens to be any damage to leaf/ beedi is not prepared properly then they subtract the amount accordingly from the wages.

The processes in beedi rolling, like filling the tobacco, tying the beedi are generally done by the female beedi worker whereas children are used for closing the open ends of tied beedi.

As beedi rolling is considered unhazardous, many women and children are involved in this process. It requires long hours of sitting at one place and handling of tobacco. Most of them roll beedies inside the house, which are already ill ventilated and overcrowded.

The actual number may be more, for every one member involved there might be one/two members who act as helping hand.

In the present study we could approach 29 beedi rollers, all of them were women.

Out of 29 participants, $9(31 \%)$ have been literate and 20 $(68.9 \%)$ have been illiterate. Majority of study participants have been Muslims (86.2\%).

In a study carried out by Rupali Sable et al., ${ }^{5}$ in urban slums of Mumbai, the mean age has been 45 years with SD of 12 years. All have been Hindus. Only females have been involved in this occupation and around $42.31 \%$ have been illiterate.

Sudharshan, ${ }^{6}$ in 1999 reported that bulk of beedi workers has been constituted by women.

In a study carried out by Padmaja Chowdhay et al., only females have been involved in this occupation. Around $42.31 \%$ have been illiterate. Among literates, those who studied till secondary and primary schooling have been 48.08 and $9.62 \%$ respectively. ${ }^{7}$ 
Similar finding has been reported by a study done by Manjula Anil et al. in Magalore where none of the beedi workers have been males. ${ }^{8}$

In the present study mean age at starting beedi rolling has been 15.4 years with minimum of 10 years and a maximum of 32 years. Mean years of involvement in beedi rolling, in the present study has been 27.5 years with minimum of 2 years and maximum of 55 years in this occupation. Out of total 29 participants, 14 (48.2\%) participants have been in this occupation since $\geq 30$ years.

In a study carried out by Padmaja chowdhary et al., ${ }^{7}$ around $26.92 \%$ of the study subjects have been in this occupation for last 21 to 30 years. Mean years of service has been 30 years and mode has been 25 years.

Source of information in majority of cases i.e. 20 (68.9\%) has been family member mainly mother, followed by relatives in case of 5 participants and neighbours as has been reported by 4 .

According to study done by Padmaja Chowdhary et al., ${ }^{7}$ Fifty women had started beedi making because their family has been in this work. Only one woman has been from Solapur, other women have been from Andhra Pradesh. Two women have been in this occupation after following the advice of neighbours.

Awareness regarding harmful effects of handling tobacco dust for rolling beedi has been known to 5 participants and 24 have been considering it to be harmless. When questioned regarding protective measures majority i.e. 19 $(65.5 \%)$ have been used to wash their hands after handling tobacco dust. But they have not been practicing any other protective measures to prevent inhalation tobacco dust and cutaneous absorption of nicotine.

Similar observation has been stated regarding safety measures by Padmaja Chowdhari et al., ${ }^{7}$ that only 43 women $(82.7 \%)$ have been washing hands after beedi making. None of them have been using masks or gloves

In present study, opinion of most of them [19 (65.5\%)] for involvement of children, pregnant females and lactating mothers has been negative as they want their children to go to school but in case of 5 participants it has been positive as they said, of whom 3 said children can be involved and 2 said pregnant females can be involved.

In another study 7, out of 52 beedi rollers, 29 had children less than 14 years, but none of them have been involved in this occupation. Most of the respondents replied that their children go to school.

Health problems due to beedi rolling like joint pains, backache have been commonly seen. Some have been suffering from giddiness, dryness of throat.
In a study by Rupali Sable et al., ${ }^{5} 78.8$ and $13.5 \%$ of the beedi roller have been suffering from aches and cough respectively.

In the present study none of the women delivered low birth baby, no one had abortion.

Findings of another study, ${ }^{7}$ showed that, out of 52 women, 10 had given birth to low birth weight baby, two of them have been taking treatment for infertility and four had premature menopause.

In the present study 6 have been suffering from Hypertension, 1 had stroke, 1 had associated DM and joint pains have been reported by 3 participants.

Regarding past history, as reported in study carried out by Padmaja Chowdhari et al., three women had suffered from tuberculosis, two had asthma and one had hemiparesis.

\section{Funding: No funding sources \\ Conflict of interest: None declared}

Ethical approval: The study was approved by the institutional ethics committee

\section{REFERENCES}

1. Rustagi P, Srivastav P, Bhardwaj P, Saha M, Vyas A, Madhu S. Survey of studies on beedi industry with special emphasis on women and child labour. New Delhi: Centre for Women's Development Studies; 2001.

2. Improving Working Conditions and Employment Opportunities for Women Beedi Workers in India. ILO's pilot action project for beedi women workers in India, 2015. Available at: http://www.ilo.org/wcmsp5/groups/public/@asia/@ ro-bangkok/@sro-

new_delhi/documents/projectdocumentation/wcms_ 125467. Accessed 4 September 2015.

3. ILO - Dept. of Labour Karnataka. The beedi sector in India - An overview - Improving working conditions and employment opportunities for women workers in beedi industry, 2001. Available at:

http://www.ilo.org/wcmsp5/groups/public/@asia/@ ro-bangkok/@sro-

new_delhi/documents/projectdocumentation/wcms 125467. Accessed 4 September 2015.

4. Mahimkar MB, Bhisey RA. Occupational exposure to tobacco increases chromosomal aberrations in tobacco processors. Mutat Res. 1995;334:139-44.

5. Rupali V. Sabale, Shobha S. Kowli, Padmaja H. Chowdhary. Working condition and health hazards in beedi rollers residing in the urban slums of Mumbai. Indian $\mathbf{J}$ Occup Environ Med. 2012;16(2):72-4. 
6. Sudarshan R, Kaur R. The tobacco industry and women's employment: old concerns and new imperatives. Indian J Labour Econ. 1999;42:675-85.

7. Padmaja H. Chowdhary, Shobha S. Kowli. Working condition and health hazards in beedi rollers residing in the urban slums of Mumbai. Indian $\mathrm{J}$ Occup Environ Med. 2012;16(2):72-4.

8. Manjula Anil, Leonard Machado, Anna Sequeira, K. S. Prasanna, Jayaram Subramanya. Study of morbidity pattern of female beedi workers in urban field practice area of Mangalore, Southern India. Int J AJ Inst Med Sci. 2012;1(1):41-6.

Cite this article as: Kollur LR, Shetty AK, Kongwad DP, Jayprakash Chowti. Status of beedi rollers in urban slum area of Dharwad city, India. Int J Community Med Public Health 2015;2:643-7. 